\title{
STUDY ON HIGH RISE STEEL TUBULAR STRUCTURESWITH BELT TRUSS SUBJECTED TO SEISMIC LOADING
}

\author{
Indumathi $\mathrm{H} \mathrm{D}^{1}$, Ganesh $\mathrm{M}^{2}$, Spandana $\mathrm{B}^{3}$ \\ ${ }^{I}$ M.Tech. (Structural Engineering), SJBIT, Department of Civil Engineering, Karnataka, India \\ ${ }^{2}$ Asst Professor, SJBIT, Department Of Civil Engineering, Karnataka, India \\ ${ }^{3}$ Asst Professor, SJBIT, Department Of Civil Engineering, Karnataka, India
}

\begin{abstract}
High rise structures are more vulnerable to earthquake loads. Hence to build this high rise structures stable an external frame works is required to increase its resistance against the seismic tremor one of such system is the belt truss systems. In this study, the response of steel tubular structures with and without the belt truss systems subjected to earthquake forces is evaluated under the seismic zone $V$ considering 70 storey steel tubular structures for analysis. The analytical method used in this dissertation work is Time History Method. Time history analysis is performed by using BHUJ earthquake data. The software utilized for the analysis is ETABS v 9.7.4. Also, the location of belt truss in the tube in tube and framed tube structures and comparison of these steel tubular structures with the steel moment resisting frames are carried out. In this work, various parameters like storey drifts, storey displacements, time period and base shear has been evaluated for different models and have been compared to obtain an efficient structure.
\end{abstract}

Keywords: Belt Truss, Tube in Tube, Framed Tube, Tubular Structures, Displacement,and Drift etc...

\section{INTRODUCTION}

In the recent years, the development of the tall buildings has been rapidly increasing in the world wide leading to the progress of the world. Primary demand by the hastily growing population and business activities to be as close to each other as possible has led to the development of the tall buildings. Tall buildings react differently from low rise structures when subjected to different lateral loading conditions due to its slender structure and hence these high rise structures introducing new challenges to the design engineers to build a resisting structure under all lateral loading conditions.

A tall building acts as a cantilevering beam from the earth and is subjected to the wind and seismic forces due to the earthquake vibrations that travels through the building creates inertial forces within the building during seismic tremor. These forces cause damage to the structures and also inconvenience to the occupants in the building. So as the height of the building increases the stiffness of the building decreases, hence to increase the stiffness and to provide the required resistance against the lateral forces a lateral load resisting system should be introduced in the building to reduce the structural and non structural damages in the buildings during seismic tremor.

Nowadays many lateral load resisting systems have come into existence that not only resists the lateral forces but also improves the overall efficiency of the buildings. Here are some of the systems which are used extensively tubular structures, rigid frame structures, coupled shear walls, outriggers systems, belt truss systems, braced frame systems etc these systems can be used individually or in combinations depending on the structures requirement for the resistance capacity.

\subsection{Tubular Structures}

Steel Tubular structures are most commonly used for high rise structures in the recent years due to its properties like strength, light weight, durability, ductility, etc. tubular structures are of three types namely Framed Tube, Tube in Tube, Braced Tube and Bundled Tube. Tubular systems consist of closely spaced columns which are interconnected by the deep spandrel beams. The main concept of the tubular structure is to form a frame which acts like a uniformly mesh or a grid like system. In tube structure, the lateral forces are resisted by rigid moment resisting exterior columns at the periphery and girders which form a tube. The transfer of the loads i.e. dead loads and live loads will take place through the vertical load bearing elements and columns which are present near the core of the tube structure.

\subsection{Belt Truss Systems}

In present tall buildings, lateral loads induced by the wind and the earthquakes forces are often resisted by a system of belt trusses. Belt trusses can be define as the truss provided to the peripheral columns of the structure around the core and at the a particular height of the building. A building can have one or more number of belt trusses at different levels within the building. Belt truss can be of concrete and steel materials with different types $\mathrm{X}, \mathrm{V}$, inverted $\mathrm{V}$ diagonal etc.

In the present study Steel Framed Tube and Tube in Tube structures are used in combination with the belt truss system 
and are analyzed by Time History Methods to know the effect of belt truss in the tubular steel structures and their location in the building. Also to investigate the efficient tubular structures with belt truss in comparison with usual beam-column steel moment resisting frame in reducing storey drift, displacement and time period.

\section{LITERATURE REVIEW}

Karthik A L, Geetha K [2016] [3] studied the dynamic analysis of bundled tube structures with belt truss and mega bracings by analyzing a 110 storey steel structure of rectangular geometry using ETABS software. In the study theyhave compared the parameters of 5 different frame works to obtain the efficient structures with and without the bracings and belt trusses. Functioning characteristics like displacements, storey drifts and base shear time periods are extracted from the analysis. From the results they observed that the steel bundled tube structures with mega bracing framework and belt truss has more stiffness and stable compared to other four structural frameworks.

Vijaya kumara Gowda MR, Manohar B C [2015][6] has studied the behavior of belt truss under different seismic zones by dynamic analysis. In this paper they have considered belt truss of different types i.e. $\mathrm{X}, \mathrm{V}$ and inverted $\mathrm{V}$ Type to know their effect in the structural systems.A 30 storey RC building is modeled using ETABS and is analyzed by using Equivalent and Response Spectrum analysis.From the analysis result they observed that,providing belt truss with the shear core reduces the storey drift, displacements and time period and also they observed that inverted $\mathrm{V}$ type concrete belt trusses are more efficient in all seismic zones.

Lakshmi S Nair, Nimiya Rose Joshuva [2016] [5] has experimented the seismic evaluation of tall structure using $\mathrm{X}$ and $\mathrm{V}$ type of belt truss with shear core for regular and torsionally irregular concrete buildings. Response Spectrum analysis for $\mathrm{G}+30$ storey building was done under seismic zone III using ETABS software. The parameters considered in this paper are storey drift, base shear, and displacement and \% reduction is calculated to know the stable structure. In case of regular building belt truss $\mathrm{X}$ and $\mathrm{V}$ showed the similar performances but in the irregular buildings belt $\mathrm{X}$ showed a better performance than belt $\mathrm{V}$.

Hanan.H.Eltobgy [2013][2] has studied the suitable locations of belt truss system in the high rise steel structure to improve its structural behavior.A 25 storey steel building is analyzed by alternate path method according to UFC09 codeusing SAAP2000 to know the optimum location of the belt truss to reduce lateral driftandto mitigate the progressive collapse in tall structures.From the results he concluded that to resist both the progressive collapseandlateral drift the belt truss should be located within the upper and lower one third of the building height.

\subsection{Methodology}

- An extensive literature review is carried to set the objectives.

- A 70 storied tubular structure of $210 \mathrm{~m}$ height with $3 \mathrm{~m}$ storey heightwith and without the belt truss system is considered

- A regular steel moment resisting frame with the same geometry as tubular structures is considered as a base model.

- Modeling and analysis is done using ETABS software.

- In both tubular structures Belt trusses are implemented at different levels i.e. at every 10storey and at every 15 storey and are analyzed.

- Time History Analysis using previous BHUJ Earthquake data is performed to understand the behavior.

- Based on the results and response of the structures conclusions are drawn.

\subsection{Objectives}

- To study the effect of belt truss in the behavior of tall tubular steel structures.

- To understand the behavior of tall tubular steel structures with the belt truss under seismic zone V

- To study the effect of location of belt truss in the tall tubular steel structures.

- Analyzing the structure using dynamic time history analysis using ETABS.

- Efficiency of tall tubular steel structure with the belt truss with respect to base shear, displacement, storey drift and time period are found out for the geometric configurations.

\section{MODELLING}

The analysis of 70 storey building is carried out using ETABS 9.7.4 software situated in zone V. The steel70 storey building is analyzed without belt truss systems and with belt truss systems also a steel moment resisting frame. Displacement, storey drift, storey shear, base shear and time period is compared for all type of structural systems i-e. With and without belt truss model.

\subsection{Modeling of Building Frames}

Building frame with the following geometrical types are considered for analysis under zone $\mathrm{V}$ for seismic loading in each case.

Model 1: Base model -steel moment resisting frame Tube in tube

Model 2: Tube in tube without belt truss

Model 3: Tube in tube with belt truss at every 10 storey

Model 4: Tube in tube with belt truss at every 15 storey

\section{Framed tube}

Model 5: Framed tube without belt truss

Model 6: Framed tube with belt truss @ every 10 storey

Model 7: Framed tube with belt truss @ every 15 storey 


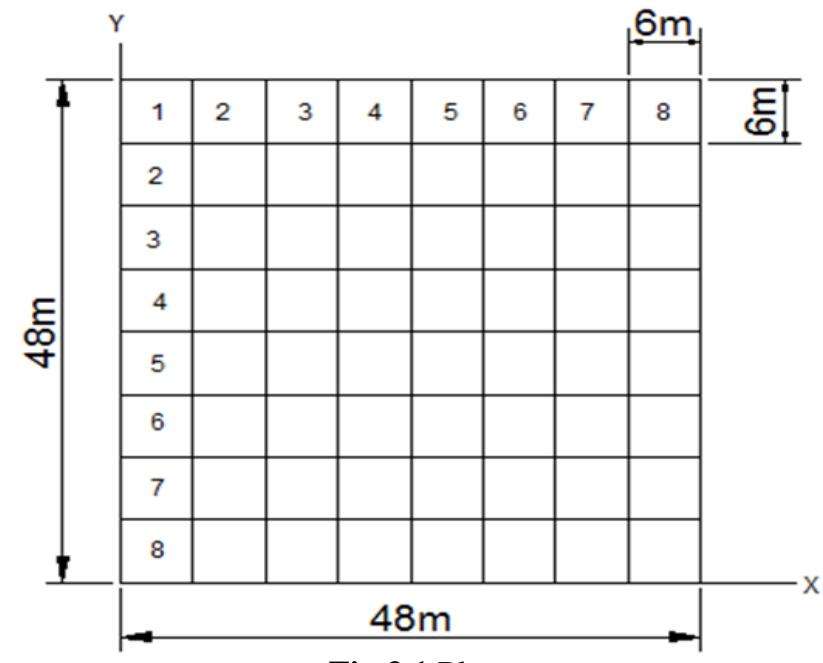

Fig.3.1 Plan

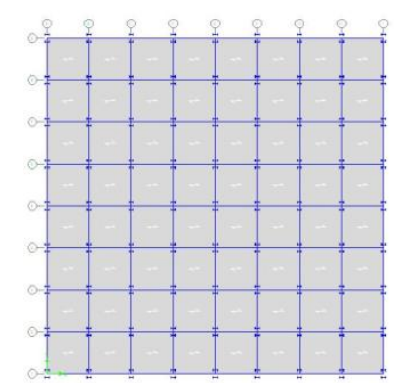

Fig.3.2.Plan of Model 1

Fig.3.3 Plan of Model 2,3,4

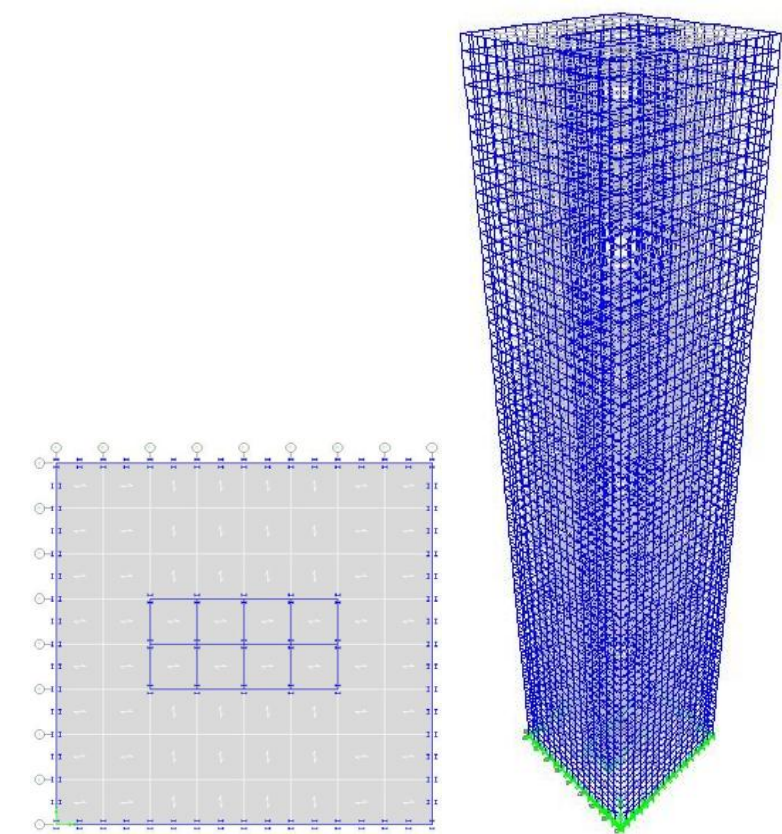

Fig.3.4 Plan of Model 5, 6 and 7 Fig.3.5 3D view of Tubular structure

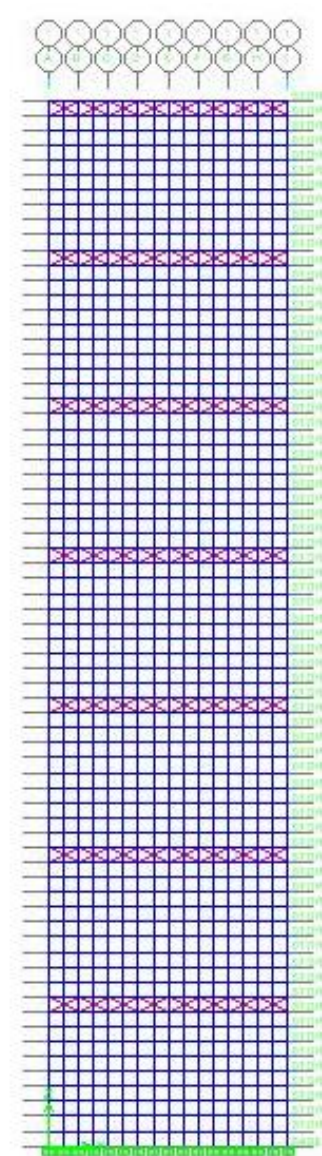

Fig.3.6 Elevation with belt truss @every 10 storey

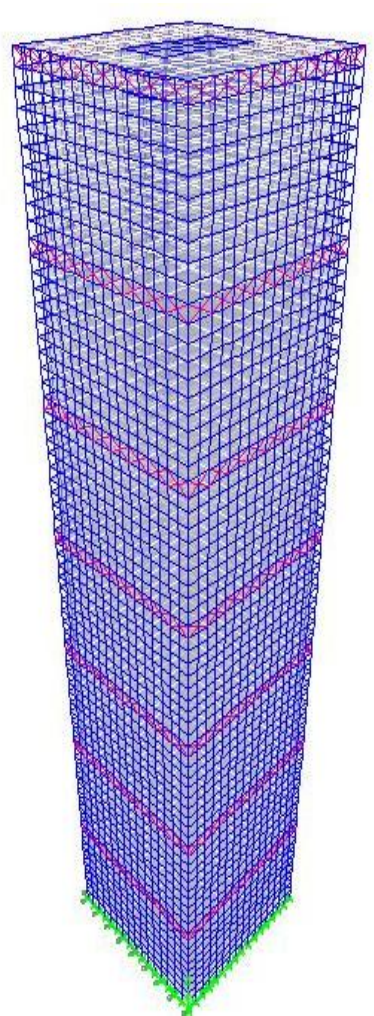

Fig.3.83D view with belt truss @every 10 storey

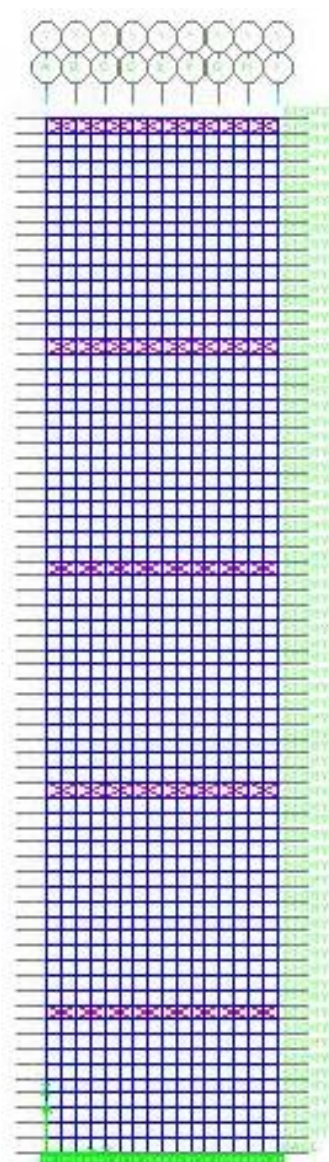

Fig.3.7 Elevation with belt truss at every 15 storey

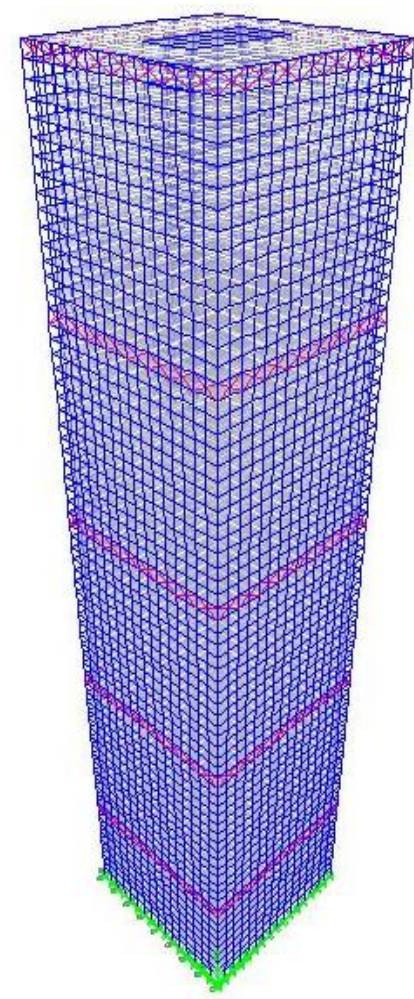

Fig.3.9 3D view with belt truss at every 15 storey 


\subsection{Material and Geometric Properties}

Following are the material properties considered for the modeling of the proposed structure frames:

Plan dimension $=48 \mathrm{~m} \times 48 \mathrm{~m}$

Storey height $=3 \mathrm{~m}$

Grid spacing along $X$ direction $=6 \mathrm{~m}$

Grid spacing along $\mathrm{Y}$ direction $=6 \mathrm{~m}$

No of stories $=70$ stories

\section{Materials property}

Grade of concrete $=$ M 30

Grade of steel $=\mathrm{Fe} 350$

Density of concrete $=25 \mathrm{kN} / \mathrm{m}^{3}$

Young's modulus of concrete $=31622 \times 10^{3} \mathrm{kN} / \mathrm{m}^{2}$

\section{Structural member details}

Column = Built-up column

Beams = ISMB 600 and ISWB 600-2

Deck $=150 \mathrm{~mm}$

Belt truss = ISMB 600, $(\mathrm{X}$ TYPE $)$

Wall thickness = glazing load is considered

\section{Load intensities}

Floor finishes $=1.5 \mathrm{kN} / \mathrm{m}^{3}$

Live load $=2 \mathrm{kN} / \mathrm{m}^{3}$

Glazing load $=1 \mathrm{kN} / \mathrm{m}^{3}$

\section{Seismic load parameters}

Zone $=\mathrm{V}$

Importance factor, $\mathrm{I}=1$

Response reduction factor, $\mathrm{R}=5$

Soil type $=$ II $=$ Medium

\section{RESULTS AND DISCUSSION}

Displacements, storey drift, base shear, time period results are extracted. Then compare the result to recognize the effective system between provided different belt truss systems under zone V. Following tables and graphs are presented to find efficient structural system.

\subsection{Top Storey Displacement}

Table.4.1 Top storey displacement

\begin{tabular}{|l|l|}
\hline Models & Top storey displacement $(\mathbf{m m})$ \\
\hline Model 1 & 61.4939 \\
\hline Model 2 & 61.9349 \\
\hline Model 3 & 55.5157 \\
\hline Model 4 & 58.1736 \\
\hline Model 5 & 72.523 \\
\hline Model 6 & 62.0711 \\
\hline Model 7 & 74.3866 \\
\hline
\end{tabular}

From the Table.4.1 and graph Fig.4.1 shows Model 7 has a higher displacement than remaining 6 models. The $\%$ reduction in displacement is $10.367 \%$ and $6.08 \%$ in model 3 and 4 with respect to Model 2. Though the belt trusses are provided in Model 7 the displacement is increased by $1.863 \mathrm{~mm}$ with respect to Model 5 . The \% reduction in Model 6 with respect to Model 5 is $14.46 \%$.

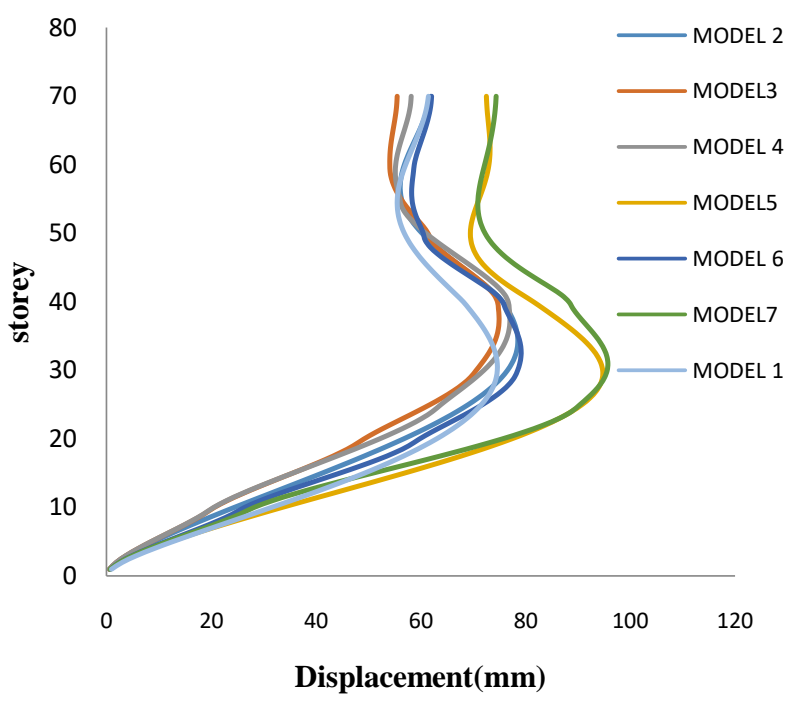

Fig.4.1: Displacements v/s storey

The percentage reduction in Model 3 with respect to Model 1 is $9.7 \%$. There is an increase in displacement of $0.23 \mathrm{~mm}$ in Model 6 with respect to Model 1.

\subsection{Storey Drift}

For drift ratios graphs are plotted for two cases, Case I: Tube in tube structures and steel moment resisting frame. Case II: Framed tube structures and steel moment resisting frame.

From the tabulated results in Table.4.2 and Fig.4.2 and Fig.4.3 following observations are done, With respect to Model 2 the \% reduction in the drift ratio is $79.79 \%$ and 67.67\% in Model 3 and Model 4 respectively. The drift ratios at the top stories are even more when it is provided with the belt truss in the Model 6 and 7 with respect to Model 5. The increase in the percentage of drift ratio is $39.39 \%$ and $20 \%$ in Model 6 and 7 with respect to the Model 5 and drift ratio is reduced only in the middle stories where the belt trusses are provided.

Table.4.2 Drift ratio

\begin{tabular}{|l|l|}
\hline Models & Top storey drift ratio \\
\hline Model 1 & 0.000063 \\
\hline Model 2 & 0.000099 \\
\hline Model 3 & 0.00002 \\
\hline Model 4 & 0.000032 \\
\hline Model 5 & 0.00002 \\
\hline Model 6 & 0.000033 \\
\hline Model 7 & 0.000025 \\
\hline
\end{tabular}

From the Fig.4.4With respect to Model 1 the $\%$ reduction in drift ratio in the Models 3 and 6 is $68 \%$ and $47.6 \%$ respectively. Max reduction is observed in Model 3. 


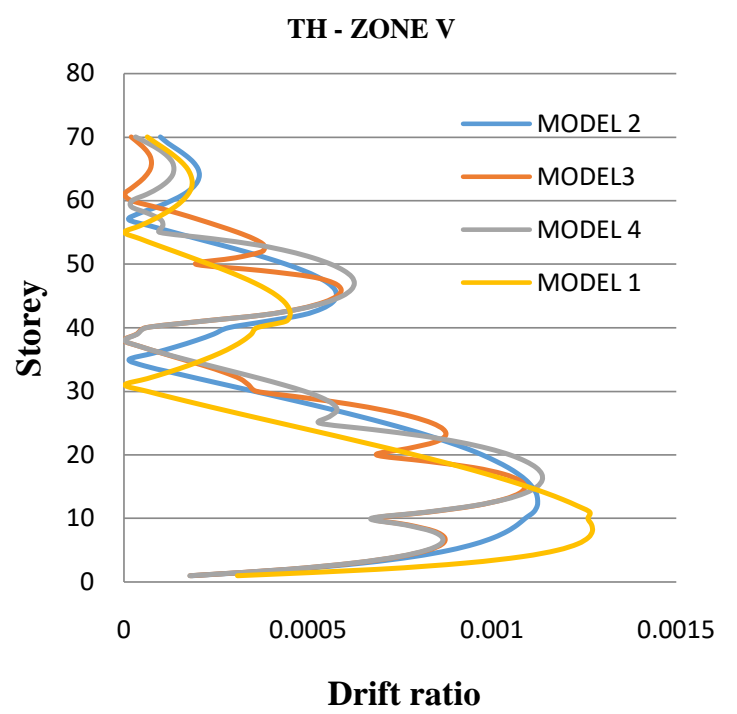

Fig.4.2: Drift ratio for Case I

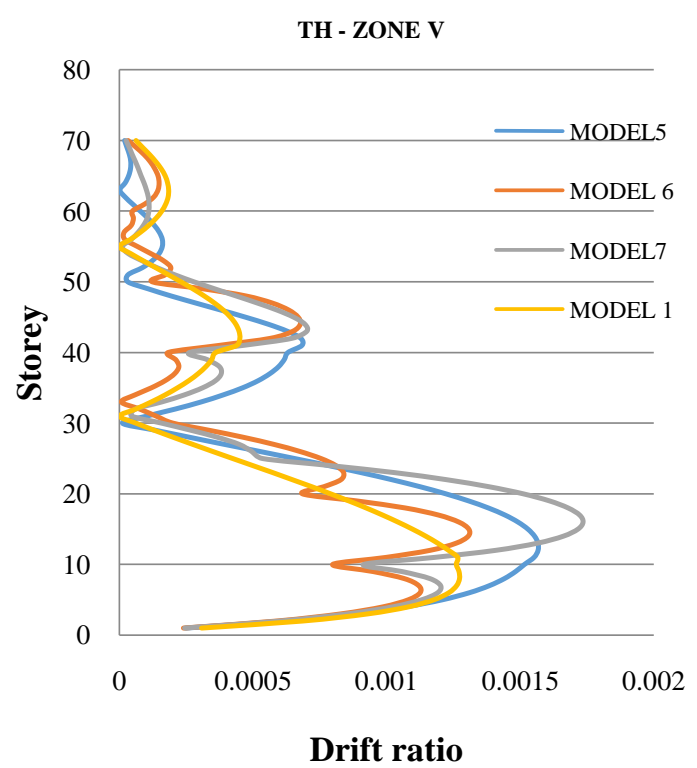

Fig.4.3: Drift ratio for Case II

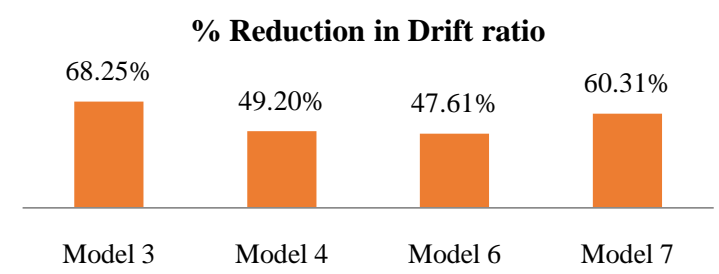

Fig.4.4: \% Reduction in Drift ratio w.r.t to Model 1

\subsection{Base Shear}

Base shear is the total design lateral force expected at the base of the structure due to the seismic ground motion at the base of the structure. Fromthe results obtained and from Fig.4.5, Base shear is increased in the models with belt truss, Base shear is relatively more for the model with the belt trusses provided at every 10 storey when compared the models with belt trusses provided at every 15 storey. Comparing to Model 1 the \% reduction of base shear is $13.78 \%$ and $3.7 \%$ in model 3 and 6 respectively.

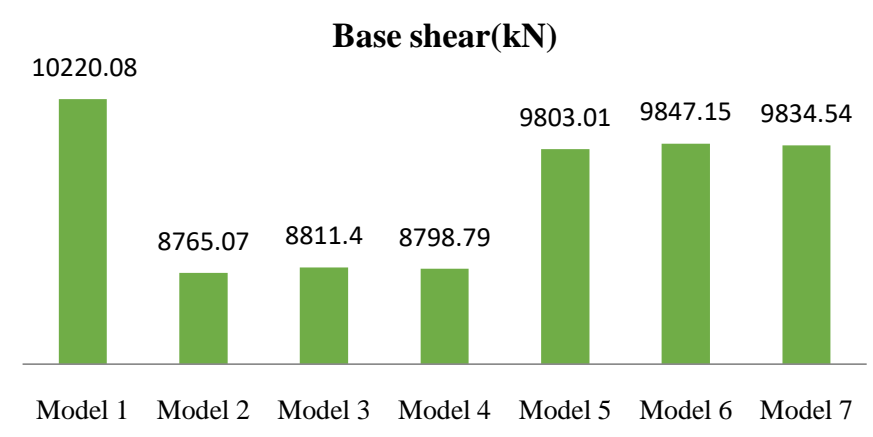

Fig.4.5 Maximumbase shear in different models

\subsection{Time Period}

From the graph Fig.4.6 shows the maximum time period obtained is $7.3 \mathrm{~s}$ for Model 5 and hence indicating that the Model 5 as the least stiffness. Models 6 and 7 has lesser period than Model 5 and Model 3 and 4 has lesser time period than Model 2 indicating the model with belt truss is slightly stiffer than Modelswithout belt truss.

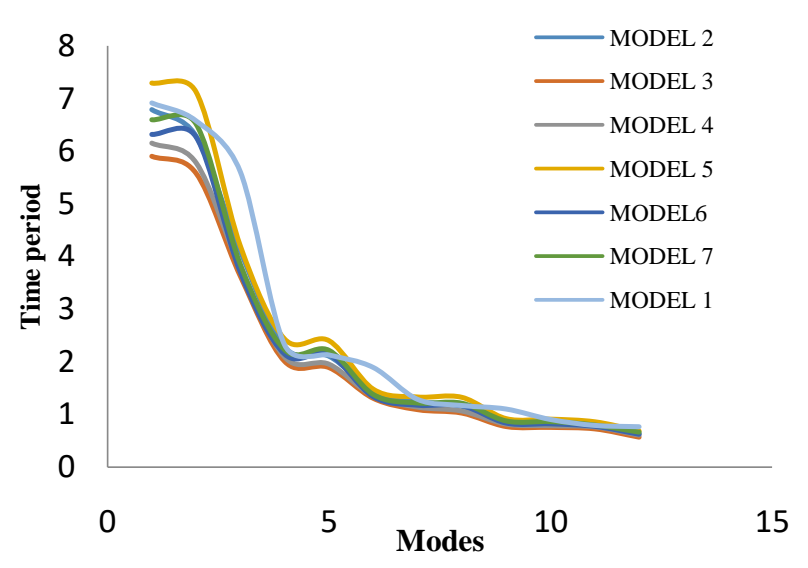

Fig.4.6 Mode of Vibrations of all models

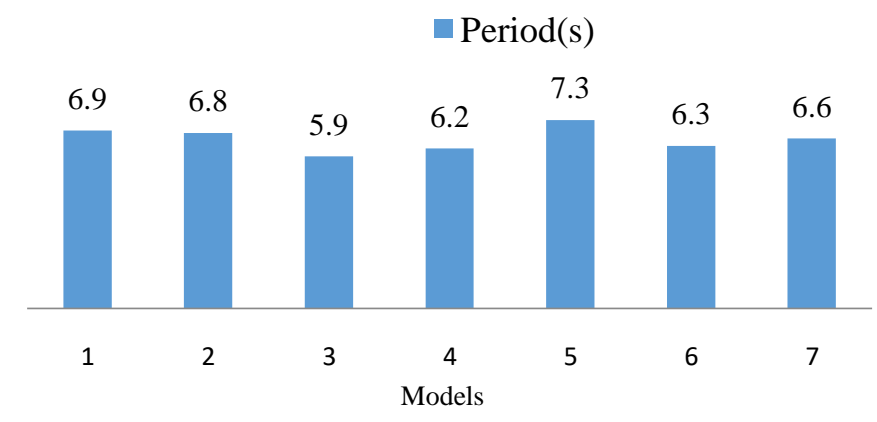

Fig.4.7 First Mode of Vibrations from all 7 Models

From Fig.4.7 Model 3 has the least time period 5.9s indicating more stiffness than other models. 


\section{CONCLUSION}

From the results obtained and the observations made through the analysis following conclusions are drawn.

1. Introducing the belt trusses in the tubular structures increases base shear.

2. Belt truss decreases the displacements in tube in tube structures and in frame tube structures only when the belt truss is placed at every 10 storey.

3. When belt truss is provided at every 10 storey in the tube in tube and framed tube model more \% reduction in displacements is observed. The \% reduction is $10.3 \%$ in tube in tube and $14.4 \%$ framed tube models with respect to those without the belt truss respectively.

4. With respect to steel moment resisting frame about $9.7 \%$ reduction in displacement is observed in tube in tube structure with belt truss provided at every 10 storey

5. In framed tube model displacement is reduced only in the middle stories at the level of belt truss, when the belt truss is introduced at every 15 storey displacement is slightly higher than the model without the belt truss at the top stories.

6. At the levels where the belt truss is provided the drift ratio is reduced in tube in tube model. $79 \%$ reduction in drift ratio is found when belt truss is provided at every 10 storey with respect to model without belt truss.

7. In framed tube, the drift ratio is reducing only in the middle where the belt truss is provided and is increasing at the top stories.

8. In tube in tube with belt truss at every 10 storey $68 \%$ reduction in drift ratio is observed with respect to steel moment resisting frame.

9. Period of vibrations are found to be less when the belt truss is provided compared to those without belt truss indicating more stiffness.

10. With respect to steel moment resisting frame, Tube in tube with belt truss has the least time period $5.9 \mathrm{~s}$ signifying more stiffness.

11. Structures with Belt truss placed at every 10 storey show better performance than belt trusses placed at every 15 storey. Hence locating belt trusses at every 10 storey increases the efficiency of the tubular structures.

12. Tube in tube structure with belt truss placed at every 10 storey is observed to be more efficient in over all aspects with respect to framed tube with and without belt truss and steel moment resisting frames.

\section{REFERENCES}

[1] Akshay A. Khanorkar, S. V. Denge,2016,"Belt Truss as Lateral Load Resisting Structural System for Tall Building: A Review", International Journal of Science Technology \& Engineering, Volume 2 , Issue 10, April 2016.

[2] Hanan H. Eltobgy "Optimum belt truss locations to enhance the structural performance of high-rise steel buildings"Wulfenia Journal Austria Vol 20, No. 6; Jun 2013

[3] Karthik A L, Geetha K "Dynamic Analysis Of Bundled Tube Steel Structure With Belt-Truss And
Mega Bracings 'International Research Journal of Engineering and Technology (IRJET) e-ISSN: 2395 -0056 Volume: 03 Issue: 07 | July-2016

[4] Krunal Z.Mistry, Dhruti J.Dhyani "Optimum Outrigger Location In Outrigger Structural System For High Rise Building" International Journal of Advance Engineering and Research Development, Volume 2, Issue 5, May -2015.

[5] Lakshmi S Nair ,Nimiya Rose Joshuva “Dynamic Analysis Of Tall Buildings With Belt Truss Systems"'C September 2016 | IJIRT | Volume 3 Issue 4 | ISSN: 2349-6002

[6] Vijaya Kumari Gowda M R, Manohar B C “A Study on Dynamic Analysis of Tall Structure with Belt Truss Systems for Different Seismic Zones 'International Journal of Engineering Research and Technology (IJERT)

[7] Vasudev M.V, Vinay Pai S. "Performance Study for Optimum Location of Multi-Outrigger and Belt Truss System in Tall Structures", IJSRD - International Journal for Scientific Research \& Development| Vol. 4, Issue 07, 2016. 